\title{
ANALISA PEMERIKSAAN GENU JOINT PROYEKSI ANTEROPOSTERIOR (AP) POSISI SUPINE DENGAN VARIASI PENYUDUTAN CENTRAL RAY
}

\author{
Dwi Laila Sukmawati ${ }^{1}$, Tris Budiyono ${ }^{2,}$, Puput Khusniatul $\mathrm{M}^{3}$,Muhammad Faik ${ }^{4}$ \\ ${ }^{13,4}$ Universitas 'Aisyiyah Yogyakarta \\ ${ }^{2}$ RSUP Dr. Sardjito
}

\begin{abstract}
ABSTRAK
Tujuan penelitian ini adalah untuk mengetahui perbedaan informasi celah sendi yang terbuka paling besar dengan variasi penyudutan central ray pada pemeriksan gепи joint. Jenis penelitian ini adalah penelitian kuantitatif deskriptif dengan pendekatan eksperimen pada tiga relawan dengan ketebalan pelvis $25 \mathrm{~cm}$, $20 \mathrm{~cm}$, dan $16 \mathrm{~cm}$ yang diukur dari anterior superior iliac spines (ASIS) ke permukaan meja pemeriksaan. Hasil penelitian menunjukkan bahwa gambaran celah sendi yang terbuka paling besar pada genu joint proyeksi Anteroposterior (AP) dengan ketebalan pelvis $25 \mathrm{~cm}$ dan $20 \mathrm{~cm}$ masing-masing $5.21 \mathrm{~mm}$ dan 8.74 $\mathrm{mm}$ pada penyudutan central ray $5^{\circ}$ cephalad. Gambaran celah sendi yang terbuka paling besar pada ketebalan pelvis $16 \mathrm{~cm}$ adalah $5.94 \mathrm{~mm}$ pada penyudutan central ray $5^{\circ}$ caudad.
\end{abstract}

Kata Kunci : Genu Joint, Central Ray, Celah Sendi, Ketebalan Pelvis

\begin{abstract}
The purpose of this study was to determine the different information on the greatest open joint gap with the variation of central ray angling in the genu joint examination. This type of research employed descriptive quantitative research with an experimental approach on three volunteers with pelvic thickness of $25 \mathrm{~cm}, 20 \mathrm{~cm}$, and $16 \mathrm{~cm}$ measured from the anterior superior iliac spines (ASIS) to the examination table surface.. The results showed that the greatest open joint gap was in the genu joint Anteroposterior projection (AP) with pelvic thickness of $25 \mathrm{~cm}$ and $20 \mathrm{~cm}$, respectively $5.21 \mathrm{~mm}$ and $8.74 \mathrm{~mm}$ at $5^{0}$ cephalad central ray obstruction. The largest open joint gap in the pelvic thickness of $16 \mathrm{~cm}$ was $5.94 \mathrm{~mm}$ in the $5^{0}$ caudad central ray angle.
\end{abstract}

Keywords : Genu Joint, Central Ray, Joint Gaps, Pelvic Thickness 


\section{Pendahuluan}

Salah satu pemeriksaan yang dilakukan kaitannya dengan pemeriksaan radiologi diagnostik adalah pemeriksaan Genu Joint. Genu joint adalah salah satu sendi kompleks dalam tubuh manusia. Femur, tibia, fibula, dan patella disatukan menjadi satu kelompok yang kompleks oleh ligamen (C. Evelyn Pearce, 2012). Sendi lutut merupakan suatu sendi yang disusun oleh beberapa tulang, ligamen beserta otot, sehingga dapat membentuk suatu kesatuan yang disebut dengan sendi lutut atau genu joint (C. Evelyn Pearce, 2012).

Beberapa hal yang diatur seperti posisi pasien, posisi objek, central point, dan central ray. Central ray adalah pusat dari berkas sinar yang digunakan dalam pemotretan (Santoso, 2016). Central ray merupakan garis lurus tengahtengah berkas sinar yang menunjukkan arah atau jalannya sinar tersebut (Santoso, 2016).

Menurut Bontrager (2014), pemeriksaan rutin yang digunakan dalam pemeriksaan radiografi genu joint yaitu proyeksi anteroposterior (AP), oblik rotasi medial (internal) dan lateral (eksternal), serta proyeksi lateral. Sedangkan menurut Bruce W. Long (2012), proyeksi anteroposterior (AP) dapat dilakukan dengan variasi penyudutan central ray tergantung pada ketebalan pelvis untuk memastikan space atau celah pada genu joint terbuka. Variasi penyudutan central ray tersebut meliputi penyudutan $5^{\circ}$ ke arah cephalad dengan ketebalan pelvis > $24 \mathrm{~cm}$, vertikal tegak lurus atau $0^{\circ}$ dengan ketebalan pelvis 19 -
$24 \mathrm{~cm}$, dan $5^{\circ}$ ke arah caudad dengan ketebalan pelvis $<19 \mathrm{~cm}$.

Pemeriksaan genu joint dilakukan proyeksi anteroposterior (AP) tanpa variasi penyudutan central ray dan umumnya $0^{0}$ atau tegak lurus terhadap kaset. Padahal dengan penggunaan central ray tanpa variasi penyudutan central ray atau tegak lurus, space pada sendi lutut atau genu joint tidak terbuka dengan baik. Variasi penyudutan central ray tersebut dilakuakn sesuai dengan ketebalan pelvis yang diukur dari dari anterior superior iliac spines (ASIS) ke permukaan meja pemeriksaan agar celah sendinya dapat terbuka dengan baik dan sejajar dengan articular facets (tibial plateau).

Berdasarkan hal tersebut, penulis tertarik membahas mengenai pemeriksaan genu joint dengan variasi penyudutan central ray agar space pada genu joint terbuka dengan baik serta dapat dipublikasikan untuk menjadi referensi dan membantu penelitian berikutnya dengan judul "Analisa Pemeriksaan Genu Joint Proyeksi Anteroposterior (AP) Posisi Supine dengan Variasi Penyudutan Central Ray".

\section{Metode}

Jenis penelitian ini adalah penelitian kuantitatif deskriptif dengan pendekatan eksperimen pada tiga relawan dengan ketebalan pelvis $25 \mathrm{~cm}, 20 \mathrm{~cm}$, dan $16 \mathrm{~cm}$ yang diukur dari anterior superior iliac spines (ASIS) ke permukaan meja pemeriksaan. Pengambilan data dilakukan dengan melakukan pemeriksaan genu joint pada tiga relawan dengan variasi penyudutan 
central ray $5^{0}$ cephalad, $0^{0}$ atau vertikal tegak lurus, dan $5^{0}$ caudad. Metode pengumpulan data yang dilakukan yaitu dengan eksperimen, wawancara mendalam kepada dokter spesialis radiologi, dan dokumentasi.

\section{Hasil dan Pembahasan}

Penelitian ini dilakukan di Laboratorium Radiologi Universitas 'Aisyiyah Yogyakarta tanggal 28 Mei 2019 pada tiga orang relawan pemeriksaan genu joint dengan masing-masing ketebalan pelvis $>24$ $\mathrm{cm}, 19-24 \mathrm{~cm}$, dan < $19 \mathrm{~cm}$ yang diukur dari anterior superior iliac spines (ASIS) atau spinac iliaca anterior superior (SIAS) ke permukaan meja pemeriksaan. Selain mengukur ketebalan pelvis, penulis juga mengukur ketebalan genu joint dari masing-masing ketebalan pelvis menggunakan meteran yang diukur dari apex patela ke permukaan meja pemeriksaan untuk mendukung pemeriksaan genu terhadap ketebalan pelvis. Adapun hasil pengukurannya adalah sebagai berikut:

Tabel 1. Ketebalan Genu Joint dan Pelvis

\begin{tabular}{|c|c|c|}
\hline $\begin{array}{c}\text { Kriteria } \\
\text { Tebal Pelvis }\end{array}$ & $\begin{array}{c}\text { Genu } \\
\text { Joint }\end{array}$ & Pelvis \\
\hline$>24 \mathrm{~cm}$ & $15 \mathrm{~cm}$ & $25 \mathrm{~cm}$ \\
\hline $19-24 \mathrm{~cm}$ & $14 \mathrm{~cm}$ & $20 \mathrm{~cm}$ \\
\hline$<19 \mathrm{~cm}$ & $12 \mathrm{~cm}$ & $16 \mathrm{~cm}$ \\
\hline
\end{tabular}

Berdasarkan pemeriksaan yang dilakukan oleh penulis mengenai pemeriksaan genu joint pada tiga orang relawan dengan ketebalan pelvis yang berbeda dan variasi penyudutan central ray di Laboratorium Radiologi Universitas 'Aisyiyah Yogyakarta didapat hasil sebagai berikut:
1. Gambaran Celah Sendi Pada Genu Joint Ketebalan Pelvis 25 $\mathrm{cm}$

a. Hasil radiograf

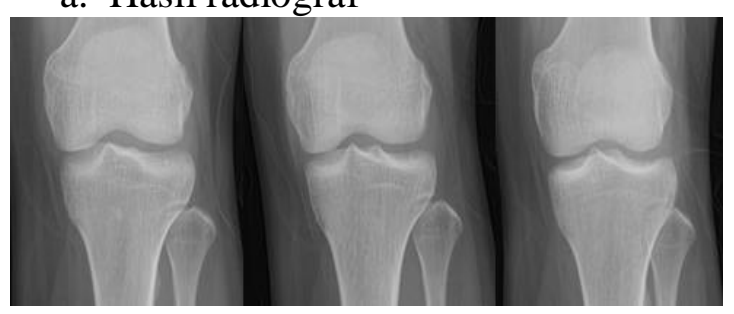

Gambar 1. Radiograf Pemeriksaan Genu Joint Proyeksi AP Supine $5^{\circ}$ Cephalad, $0^{\circ}$ atau Tegak Lurus, $5^{\circ}$ Caudad Pada Relawan 1

Berdasarkan hasil radiograf pada gambar 1, pada penyudutan central ray $5^{\circ}$ cephalad tampak superposisi di sisi medial serta intercondylar eminence pada penyudutan central ray $5^{\circ}$ cephalad. Pada penyudutan central ray $0^{\circ}$ atau tegak lurus, intercondylar eminence lebih menonjol. Pada penyudutan central ray $5^{\circ}$ caudad, femur dan tibia terpisah, tampak jelas dan tajam.

b. Hasil pengukuran celah sendi dari fossa intercondylar ke intercondylar eminence dengan ketebalan pelvis $25 \mathrm{~cm}$

Tabel 2. Hasil Ukur Celah Sendi Dari Fossa Intercondylar ke Intercondylar Eminence Ketebalan Pelvis 25

$\mathrm{cm}$

\begin{tabular}{|l|l|}
\hline $\begin{array}{l}\text { Variasi Penyudutan } \\
\text { Central Ray }\end{array}$ & Hasil Ukur \\
\hline $5^{\circ}$ Cephalad & $5.21 \mathrm{~mm}$ \\
\hline $\begin{array}{l}0^{\circ} \text { atau Tegak } \\
\text { Lurus }\end{array}$ & $4.34 \mathrm{~mm}$ \\
\hline $5^{\circ}$ Caudad & $4.95 \mathrm{~mm}$ \\
\hline
\end{tabular}

Berdasarkan tabel 2 diketahui bahwa gambaran celah sendi yang 
terbuka paling besar pada ketebalan pelvis $25 \mathrm{~cm}$ adalah $5.21 \mathrm{~mm}$ pada penyudutan central ray $5^{\circ}$ cephalad. Pada penyudutan central ray $0^{\circ}$ atau tegak lurus, besarnya celah sendi yang terbuka yaitu $4.34 \mathrm{~mm}$. Pada penyudutan central ray $5^{\circ}$ caudad, besarnya celah sendi yang terbuka yaitu $4.95 \mathrm{~mm}$.

2. Gambaran Celah Sendi Pada Genu Joint Ketebalan Pelvis 20 $\mathrm{cm}$

a. Hasil radiograf

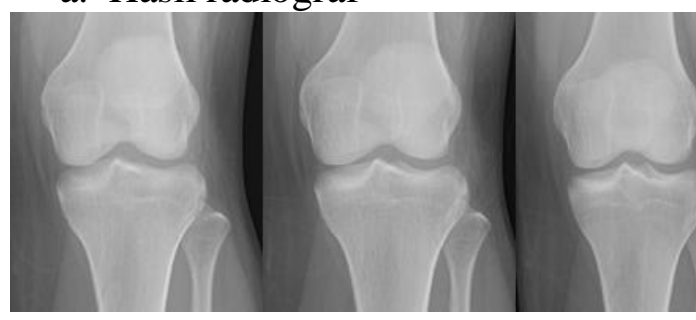

Gambar 2. Radiograf Pemeriksaan Genu Joint Proyeksi AP Supine $5^{\circ}$ Cephalad, $0^{\circ}$ atau Tegak Lurus, 5

- Caudad Pada Relawan 2

Berdasarkan hasil radiograf pada gambar 2, pada penyudutan central ray $5^{\circ}$ cephalad tampak permukaan sendi lebih lebar. Pada penyudutan central ray $5^{\circ}$ cephalad dan $0^{\circ}$ atau tegak lurus tampak superposisi di sisi medial. Pada penyudutan central ray $5^{\circ}$ caudad, tampak gambaran lebih tajam dan jelas.

b. Hasil pengukuran celah sendi dari fossa intercondylar ke intercondylar eminence dengan ketebalan pelvis $20 \mathrm{~cm}$

Tabel 3. Hasil Ukur Celah Sendi Dari FossaIntercondylar ke Intercondylar Eminence

Ketebalan Pelvis $20 \mathrm{~cm}$

\begin{tabular}{|l|c|}
\hline \multicolumn{1}{|c|}{$\begin{array}{c}\text { Variasi } \\
\text { Penyudutan } \\
\text { Central Ray }\end{array}$} & $\begin{array}{c}\text { Hasil } \\
\text { Ukur }\end{array}$ \\
\hline $5^{\circ}$ Cephalad & $8.74 \mathrm{~mm}$ \\
\hline $\begin{array}{l}0^{\circ} \text { atau Tegak } \\
\text { Lurus }\end{array}$ & $7.13 \mathrm{~mm}$ \\
\hline $5^{\circ}$ Caudad & $5.29 \mathrm{~mm}$ \\
\hline \multicolumn{1}{|c|}{ Berdasarkan tabel $\quad 3$}
\end{tabular}

diketahui bahwa gambaran celah sendi yang terbuka paling besar pada ketebalan pelvis $20 \mathrm{~cm}$ adalah $8.74 \mathrm{~mm}$ pada penyudutan central ray $5^{\circ}$ cephalad. Pada penyudutan central ray $0^{\circ}$ atau tegak lurus, besarnya celah sendi yang terbuka yaitu $7.13 \mathrm{~mm}$. Pada penyudutan central ray $5^{\circ}$ caudad, besarnya celah sendi yang terbuka yaitu 5.29 $\mathrm{mm}$.

3. Gambaran Celah Sendi Pada Genu Joint Ketebalan Pelvis 16 $\mathrm{cm}$

a. Hasil radiograf

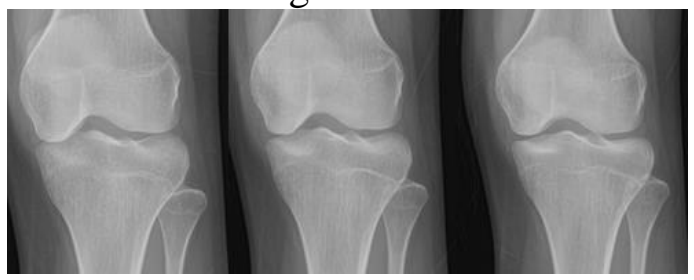

Gambar 3. Radiograf Pemeriksaan Genu Joint Proyeksi AP Supine $5^{\circ}$ Cephalad, $0^{\circ}$ atau Tegak Lurus, $5^{\circ}$ Caudad Pada Relawan 3

Berdasarkan hasil radiograf pada gambar 3, pada penyudutan central ray $5^{\circ}$ cephalad tampak superposisi di sisi medial sehingga 
intercondylar eminence tidak jelas serta meyempit. Pada penyudutan central ray $0^{\circ}$ atau tegak lurus tampak superposisi di sisi medial, terlihat lebih lebar, condylus medial antara femur dan tibia superposisi. Pada peyudutan central ray $5^{\circ}$ caudad, radiograf tampak terbuka dan lebih sempit, tampak jelas dan tajam, tibia dan fibula terpisah.

b. Hasil pengukuran celah sendi dari fossa intercondylar ke intercondylar eminence dengan ketebalan pelvis $16 \mathrm{~cm}$

Tabel 4. Hasil Ukur Celah Sendi Dari Fossa Intercondylar ke Intercondylar Eminence Ketebalan Pelvis 16 $\mathrm{cm}$

\begin{tabular}{|l|c|}
\hline \multicolumn{1}{|c|}{$\begin{array}{c}\text { Variasi } \\
\text { Penyudutan } \\
\text { Central Ray }\end{array}$} & $\begin{array}{c}\text { Hasil } \\
\text { Ukur }\end{array}$ \\
\hline $5^{\circ}$ Cephalad & $5.76 \mathrm{~mm}$ \\
\hline $\begin{array}{l}0^{\circ} \text { atau Tegak } \\
\text { Lurus }\end{array}$ & $5.23 \mathrm{~mm}$ \\
\hline $5^{\circ}$ Caudad & $5.94 \mathrm{~mm}$ \\
\hline
\end{tabular}

Berdasarkan tabel 4 diketahui bahwa gambaran celah sendi yang terbuka paling besar pada ketebalan pelvis 20 $\mathrm{cm}$ adalah $5.94 \mathrm{~mm}$ pada penyudutan central ray $5^{\circ}$ caudad. Pada penyudutan central ray $5^{\circ}$ cephalad, besarnya celah sendi yang terbuka yaitu $5.76 \mathrm{~mm}$. Pada penyudutan central ray $0^{\circ}$ atau tegak lurus, besarnya celah sendi yang terbuka yaitu 5.23 $\mathrm{mm}$.
Berdasarkan hasil radiograf setelah dilakukan pengukuran dengan menggunakan tools measurement pada DR unit, gambaran celah sendi yang terbuka pada genu joint berdasarkan ketebalan pelvis yang diukur dari fossa intercondylar sampai ke intercondylar eminence adalah sebagai berikut:

1. Gambaran Celah Sendi Pada Genu Joint Ketebalan Pelvis 25 $\mathrm{cm}$

Gambaran celah sendi yang terbuka paling besar pada genu joint proyeksi Anteroposterior (AP) dengan ketebalan pelvis > $24 \mathrm{~cm}$ dalam hal ini $25 \mathrm{~cm}$ adalah $5.21 \mathrm{~mm}$ pada penyudutan central ray $5^{\circ}$ cephalad. Hal tersebut sesuai menurut Bontrager (2014), jika ketebalan pelvis > $24 \mathrm{~cm}$, central ray yang tepat untuk memastikan celah sendi terbuka dengan baik yaitu diatur $3^{0}-5^{0}$ cephalad.

Menurut penulis, pengaturan central ray $3^{0}-5^{0}$ cephalad dilakukan karena ketebalan pelvis membuat genu terangkat sehingga bagian distal femur dan tibial plataeu superposisi . Menurut Bontrager (2014), central ray sejajar dengan articular facets (tibial plateu) untuk terbukanya celah sendi dengan mengukur jarak dari anterior superior iliac spines (ASIS) ke permukaan meja pemeriksaan sehingga sudut central ray dapat ditentukan melalui pengukuran tersebut. Tetapi penyudutan tersebut dapat dilakukan untuk ukuran yang lebih kecil dengan pengaturan sudut $3^{0}$ cephalad. Semakin besar ketebalan pelvis yang diukur dari 
SIAS sampai ke permukaan meja pemeriksaan, maka central ray diatur semakin besar.

Berdasarkan hasil radiograf pemeriksaan genu joint proyeksi Anteroposterior (AP) dengan variasi penyudutan central ray pada ketebalan pelvis $25 \mathrm{~cm}$, kriteria yang tampak adalah sebagai berikut:

a. Ketebalan Pelvis $25 \mathrm{~cm}$ Penyudutan Central Ray $5^{\circ}$ Cephalad

Kriteria radiograf pada ketebalan pelvis $25 \mathrm{~cm}$ penyudutan central ray $5^{\circ}$ cephalad adalah tampak distal femur, proximal tibia dan fibula.. Patella dan tibia superposisi dengan femur. Tampak epicondylus lateral dan medial. Bagian medial dari caput fibula superposisi dengan tibia. Intercondylar eminence tampak jelas hampir tepat berada pada pertengahan fossa intercondylar. Femoral condyles simetris. Tibia intercondylar tidak tepat berada di tengah atau tidak terpusat.

b. Ketebalan Pelvis $25 \mathrm{~cm}$ Penyudutan Central Ray $0^{\circ}$ atau Tegak Lurus

Kriteria radiograf pada ketebalan pelvis $25 \mathrm{~cm}$ penyudutan central ray $0^{\circ}$ atau tegak lurus adalah tampak distal femur, proximal tibia dan fibula. Patella superposisi dengan femur. Tampak epicondylus lateral dan medial. Bagian medial dari caput fibula setengahnya superposisi dengan tibia. Intercondylar eminence tidak tepat berada pada pertengahan fossa intercondylar. Tibia intercondylar tidak tepat berada di tengah atau tidak terpusat. Interspace di kedua sisi tidak sama dan lebih besar di daerah lateral dan intercondylar eminence lebih menonjol.

c. Ketebalan Pelvis $25 \mathrm{~cm}$ Penyudutan Central Ray $5^{\circ}$ Caudad

Kriteria radiograf pada ketebalan pelvis $25 \mathrm{~cm}$ penyudutan central ray $5^{\circ}$ caudad adalah tampak distal femur, proximal tibia dan fibula. Femorotibial joint space tampak terbuka dan jika dibandingkan dengan penyudutan $5^{\circ}$ cephalad dan $0^{\circ}$ atau tegak lurus, interspace lebih baik karena besarnya hampir sama. Patella superposisi dengan femur. Tampak epicondylus lateral dan medial. Bagian medial dari caput fibula setengahnya superposisi dengan tibia dan terlihat jelas. Intercondylar eminence tidak tepat berada pada pertengahan fossa intercondylar dan lebih mengarah ke sisi medial. Lateral dan medial tibial plateau terbuka dan seimbang.

2. Gambaran Celah Sendi Pada Genu Joint Ketebalan Pelvis 20 $\mathrm{cm}$

Gambaran celah sendi yang terbuka paling besar pada genu joint proyeksi Anteroposterior (AP) dengan ketebalan pelvis 19$24 \mathrm{~cm}$ adalah $8.74 \mathrm{~mm}$ pada penyudutan central ray $5^{\circ}$ 
cephalad. Hal tersebut tidak sesuai dengan teori. Menurut Bontrager (2014), ketebalan pelvis 19-24 cm yang diukur dari anterior superior iliac spines (ASIS) ke permuakaan meja pemeriksaan dengan sudut $0^{0}$ atau vertikal tegak lurus terhadap kaset baik untuk membuka celah sendi karena articular facets (tibial plateau) sejajar dengan central ray.

Pada penyudutan central ray $0^{\circ}$ atau vertikal tegak lurus, besarnya celah sendi yang terbuka yaitu $7.13 \mathrm{~mm}$. Besarnya celah sendi yang terbuka pada penyudutan central ray $0^{0}$ atau verikal tegak lurus terhadap kaset yang diukur dari fossa intercondylar ke intercondylar eminence tersebut lebih kecil dibandingkan dengan penyudutan $5^{0}$ cephalad. Hal tersebut menurut penulis dapat diakibatkan oleh sudut tabung yang tidak terkalibrasi dengan baik, selain itu bisa diakibatkan karena relawan yang memiliki kelainan meskipun telah dipastikan tidak memiliki penyakit di genu, dan dapat juga diakibatkan oleh central point yang tidak tepat karena pada saat dilakukan pemeriksaan tidak diberikan fiksasi sehingga memungkinkan untuk terjadinya pergerakan yang menyebabkan central point yang telah diatur bergeser serta central ray tidak sejajar dengan articular facets (tibial plateu) yang mengakibatkan celah sendi yang diukur dari fossa intercondylar ke intercondylar eminence lebih kecil.
Berdasarkan hasil radiograf pemeriksaan genu joint proyeksi Anteroposterior (AP) dengan variasi penyudutan central ray pada ketebalan pelvis $20 \mathrm{~cm}$, kriteria yang tampak adalah sebagai berikut:

a. Ketebalan Pelvis $20 \mathrm{~cm}$ Penyudutan Central Ray $5^{\circ}$ Cephalad

Kriteria radiograf pada ketebalan pelvis $20 \mathrm{~cm}$ penyudutan central ray $5^{\circ}$ cephalad adalah tampak distal femur, proximal tibia dan fibula. Femorotibial joint space tampak terbuka dan lebih besar pada sisi lateral. Patella superposisi dengan femur. Tampak epicondylus lateral dan medial. Bagian medial dari caput fibula setengahnya superposisi dengan tibia. Intercondylar eminence tidak tepat berada pada pertengahan fossa intercondylar dan mengarah ke sisi lateral.

b. Ketebalan Pelvis $20 \mathrm{~cm}$ Penyudutan Central Ray $0^{\circ}$ atau Tegak Lurus

Kriteria radiograf pada ketebalan pelvis $20 \mathrm{~cm}$ penyudutan central ray $0^{\circ}$ atau tegak lurus adalah tampak distal femur, proximal tibia dan fibula. Patella superposisi dengan femur. Tampak epicondylus lateral dan medial. Bagian medial dari caput fibula setengahnya superposisi dengan tibia. Intercondylar eminence tidak tepat berada pada pertengahan fossa intercondylar dan lebih mengarah ke sisi lateral. 
c. Ketebalan Pelvis $20 \mathrm{~cm}$ Penyudutan Central Ray $5^{\circ}$ Caudad

Kriteria radiograf pada ketebalan pelvis $20 \mathrm{~cm}$ penyudutan central ray $5^{\circ}$ caudad adalah tampak distal femur, proximal tibia dan fibula. Patella superposisi dengan femur dan terlihat berada di tengah. Tampak epicondylus lateral dan medial. Bagian medial dari caput fibula setengahnya superposisi dengan tibia.

3. Gambaran Celah Sendi Pada Genu Joint Ketebalan Pelvis 16 $\mathrm{cm}$

Gambaran celah sendi yang terbuka paling besar pada genu joint proyeksi Anteroposterior (AP) dengan ketebalan pelvis $<19 \mathrm{~cm}$ adalah $5.94 \mathrm{~mm}$ pada penyudutan central ray $5^{\circ}$ caudad. Hal tersebut sesuai dengan teori menurut Bontrager (2014) mengenai penentuan central ray yang tepat agar sejajar dengan articular facets (tibial plateau) untuk celah sendi yang terbuka dengan mengukur jarak dari anterior superior iliac spine (ASIS) ke meja ditentukan sudut central ray $3^{0}-5^{0}$ caudad dengan ketebalan $<19 \mathrm{~cm}$.

Menurut penulis pada gambar 2.7, tampak sisi distal femur mengarah ke arah caudad karena ketebalan pelvis yang diukur dari ASIS ke permukaan meja pemeriksaan menurun sehingga penyudutan central ray yang tepat yaitu $3^{0}-5^{0}$ ke arah caudad. Dalam hal ini, penulis menggunakan penyudutan centraal ray $5^{0}$ caudad. Pengaturan penyudutan central ray tersebut dilakukan apabila ketebalannya semakin kecil, maka penyudutan central ray semakin kecil agar central ray sejajar dengan articular facets (tibial plateu) sehingga celah sendi dapat terbuka dengan baik.

Berdasarkan hasil radiograf pemeriksaan genu joint proyeksi Anteroposterior (AP) dengan variasi penyudutan central ray pada ketebalan pelvis $20 \mathrm{~cm}$, kriteria yang tampak adalah sebagai berikut:

a. Ketebalan Pelvis $16 \mathrm{~cm}$ Penyudutan Central Ray $5^{\circ}$ Cephalad

Kriteria radiograf pada ketebalan pelvis $16 \mathrm{~cm}$ penyudutan central ray $5^{\circ}$ cephalad adalah tampak distal femur, proximal tibia dan fibula. Femorotibial joint space tidak terbuka dengan baik pada sisi lateral dan medial, tetapi pada bagian tengah terbuka dan space fossa intercondylar dengan intercondylar eminence tidak tepat berada di tengah dan mengarah ke sisi lateral. Patella superposisi dengan femur dan condong ke sisi medial dan tampak melewati distal femur. Tampak epicondylus lateral dan medial.

b. Ketebalan Pelvis $16 \mathrm{~cm}$ Penyudutan Central Ray $0^{\circ}$ atau Tegak Lurus

Kriteria radiograf pada ketebalan pelvis $16 \mathrm{~cm}$ penyudutan central ray $0^{\circ}$ atau tegak lurus adalah tampak distal femur, proximal tibia dan fibula. Femorotibial joint 
space tampak terbuka lebih besar di sisi lateral dan di sisi medial lebih sempit. Patella superposisi dengan femur. Tampak epicondylus lateral dan medial. Bagian medial dari caput fibula setengahnya superposisi dengan tibia. Intercondylar eminence tidak tepat berada pada pertengahan fossa intercondylar karena mengarah ke sisi lateral.

c. Ketebalan Pelvis $16 \mathrm{~cm}$ Penyudutan Central Ray $5^{\circ}$ Caudad

Kriteria radiograf pada ketebalan pelvis $16 \mathrm{~cm}$ penyudutan central ray $5^{\circ}$ caudad adalah tampak distal femur, proximal tibia dan fibula. Femorotibial joint space tampak terbuka baik di sisi medial dan lateral, tetapi lebih besar pada sisi lateral. Patella superposisi dengan femur dan tampak di sisi condylus medial. Tampak epicondylus lateral dan medial.

\section{Simpulan}

1. Gambaran celah sendi yang terbuka paling besar pada genu joint proyeksi Anteroposterior (AP) dengan ketebalan pelvis > $24 \mathrm{~cm}$ adalah $5.21 \mathrm{~mm}$ pada penyudutan central ray $5^{\circ}$ cephalad.

2. Gambaran celah sendi yang terbuka paling besar pada genu joint proyeksi Anteroposterior (AP) dengan ketebalan pelvis 19$24 \mathrm{~cm}$ adalah $8.74 \mathrm{~mm}$ pada penyudutan central ray $5^{\circ}$ cephalad.
3. Gambaran celah sendi yang terbuka paling besar pada genu joint proyeksi Anteroposterior (AP) dengan ketebalan pelvis $<19 \mathrm{~cm}$ adalah $5.94 \mathrm{~mm}$ pada penyudutan central ray $5^{\circ}$ caudad

\section{Saran}

1. Pada pemeriksaan genu joint proyeksi anteroposterior (AP) sebaiknya central point tepat 1.25 $\mathrm{cm}$ di bawah apex patela dengan memberikan fiksasi untuk mengurangi pergerakan sehingga tidak mempengaruhi hasil dan tepat sejajar mengenai articular facets (tibial plateu) agar celah sendi dapat terbuka dengan baik.

2. Pada pemeriksaan genu joint sebaiknya proyeksi lateral dilakukan terlebih dahulu dengan arah sinar horizontal tegak lurus terhadap kaset sebelum proyeksi anteroposterior (AP) guna mengetahui penyudutan central ray yang paling tepat dan sejajar dengan articular facets (tibial plate) agar celah sendi dapat terbuka dengan baik.

\section{Daftar Pustaka}

Bontrager, Kenneth L. dan John P. Lampignano. 2014. Textbook of Radiographic Positioning and Related Anatomy, Eighth Edition. St..Louis: CV. Mosby Company.

Long, Bruce W., Jeannean Hall Rollins, dan Barbara J. Smith. 2012. Merrill's Atlas of Radiographic Positioning and Procedures, Thirteenth Edition, Volume One. St..Louis: Mosby Inc. 
Pearce, Evelyn, C. 2012. Anatomi dan fisiologi untuk paramedis. Jakarta: Penerbit PT. Gramedia Pustaka Utama.

Santoso, dkk. 2016. Penentuan Faktor Eksposi Pada Pembangkit Sinar-X Konvensional Dengan Menggunakan Logika Fuzzy. Prosiding SNST ke-7 Tahun 2016. Fakultas Teknik Universitas Wahid Hayim Semarang. 